\title{
Shear-Deformation-Induced Modification of Defect Structures and Hierarchical Microstructures in Miscible and Immiscible Alloys
}

Bharat Gwalani ${ }^{1}$, Miao Song ${ }^{1}$, Julian Escobar ${ }^{1}$, Anqi Yu ${ }^{1}$, Matthew Olszta ${ }^{2}$, Jia Liu ${ }^{1}$, Tingkun Liu ${ }^{1}$, Joshua Silverstein ${ }^{1}$, Xiaolong $\mathrm{Ma}^{3}$, Suveen mathaudhu ${ }^{3}$, Peter Sushko ${ }^{3}$, Cynthia Powell ${ }^{1}$ and Arun Devaraj $^{3}$

${ }^{1}$ Pacific Northwest National Lab, Richland, Washington, United States, ${ }^{2}$ Pacific Northwest National Laboratory, Washington, United States, ${ }^{3}$ PNNL, United States

Shear-based deformation is used for several advanced materials' processing methods such a friction-stirbased processing, welding, or additive manufacturing[1-5]. In these processes, the mechanical-thermal coupling obscures a deep mechanistic understanding of the microstructural evolution of multi-phase metallic systems under extreme shear deformation, and the knowledge of how these microstructures influence mechanical properties is in its nascency (Figure 1). The challenge arises from the complexity and interdependent nature of many atomic-scale to macroscale phenomena that can occur when materials are subjected to shear deformation-based processing. Using multi-modal correlative microscopy techniques and computational simulations, the change in dislocation density and local misorientations, grain/phase boundary migration, dynamic recrystallization, and further deformation of recrystallized microstructures during the processing are characterized. In this work, we highlight the influence of shear deformation on the microstructural hierarchy and mechanical properties of binary alloys such as $\mathrm{Al}-\mathrm{Si}, \mathrm{Cu}-\mathrm{X}(\mathrm{X}=\mathrm{Nb}, \mathrm{Cr}$ or $\mathrm{Ni})$. Our studies show that shear-deformation-induced grain refinement, multiscale fragmentation, and metastable solute saturated phases with distinctive defect structures lead to a significant increase in the flow stresses measured via micropillar compression[6]. These results highlight that shear deformation during solid-phase processing can achieve persistently metastable microstructures with enhanced mechanical properties alloys with varying solute miscibility. The experimental insights obtained here are crucial for developing atomic-scale to mesoscale predictive models for microstructural evolution of alloys under high strain shear deformation. 


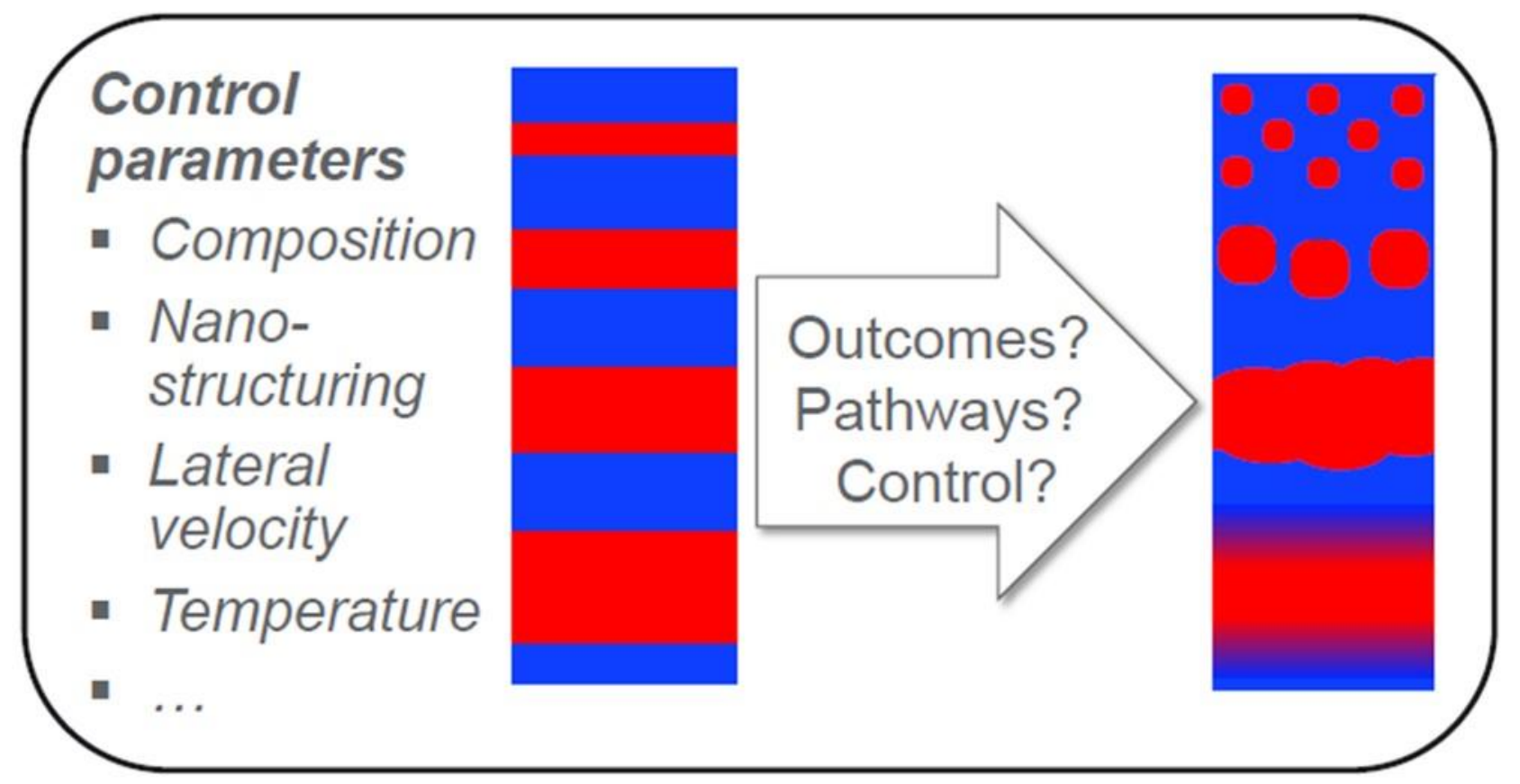

Figure 1. Figure 1. Schematic showing the present knowledge gap in the understanding the influence of processing parameters on the final material microstructure in solid phase processing

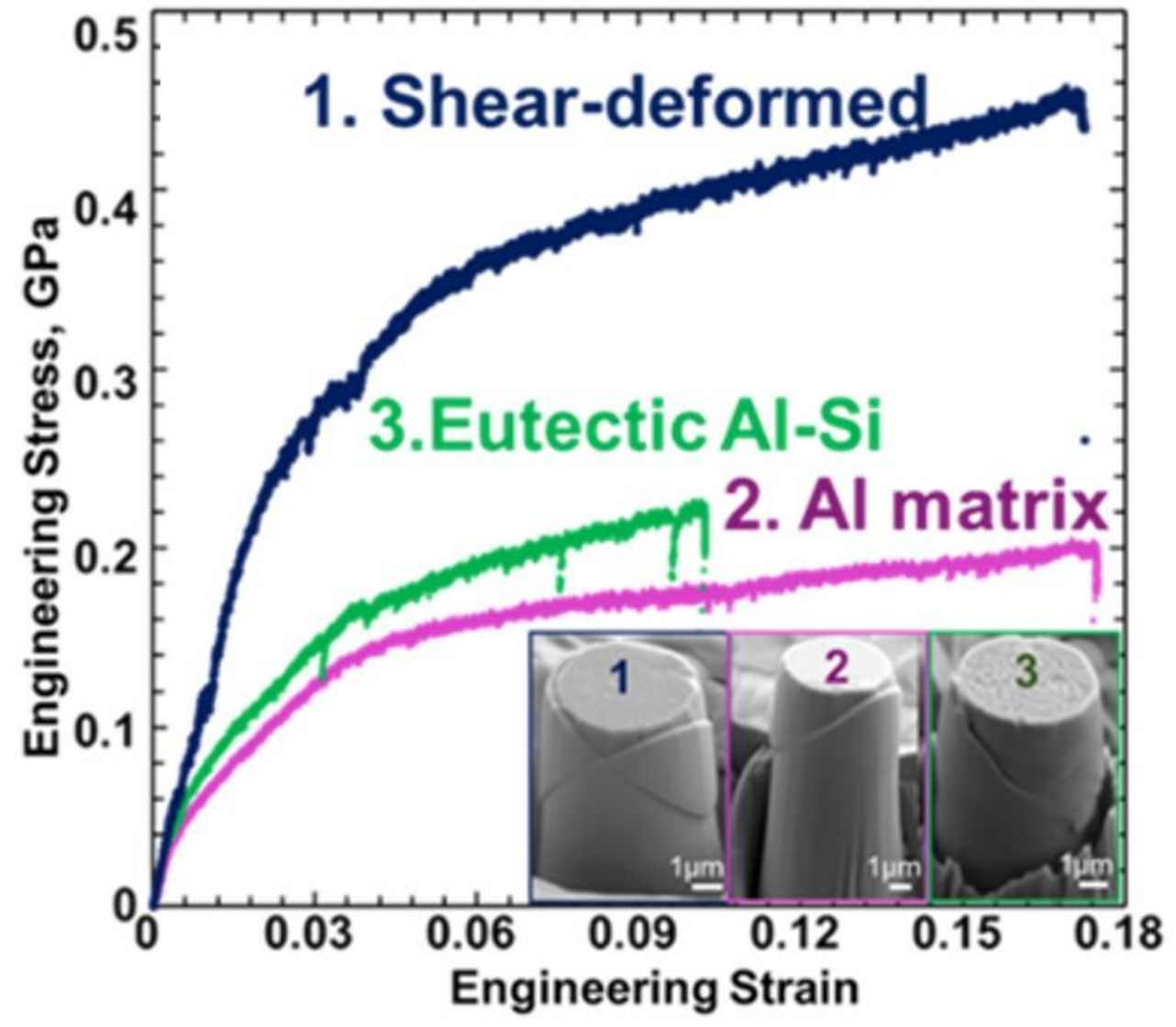


Figure 2. Figure 2: Nanomechanical testing if shear processed and as-cast microstructures show a 2-fold improvement in the mechanical properties after solid state shear processing of alloys (reproduced from published article[6]).

References

[1] D. Hrishikesh, U. Piyush, T. Wang, G. Bharat, X. Ma, Interfacial reaction during friction stir assisted scribe welding of immiscible Fe and Mg alloy system, Scientific Reports (Nature Publisher Group), 11 (2021).

[2] T. Wang, B. Gwalani, J. Silverstein, J. Darsell, S. Jana, T. Roosendaal, A. Ortiz, W. Daye, T. Pelletiers, S. Whalen, Microstructural Assessment of a Multiple-Intermetallic-Strengthened Aluminum Alloy Produced from Gas-Atomized Powder by Hot Extrusion and Friction Extrusion, Materials, 13 (2020) 5333.

[3] X. Li, N. Overman, T. Roosendaal, M. Olszta, C. Zhou, H. Wang, T. Perry, J. Schroth, G. Grant, Microstructure and Mechanical Properties of Pure Copper Wire Produced by Shear Assisted Processing and Extrusion, Jom-Us, 71 (2019) 4799-4805.

[4] Y. Li, S. Hu, E. Barker, N. Overman, S. Whalen, S. Mathaudhu, Effect of grain structure and strain rate on dynamic recrystallization and deformation behavior: A phase field-crystal plasticity model, Computational Materials Science, 180 (2020) 109707.

[5] N. Overman, X. Li, M. Olszta, E. Nickerson, C. Overman, S. Mathaudhu, G. Grant, S. Whalen, Microstructural progression of shear-induced mixing in a CuNi alloy, Materials Characterization, (2020) 110759.

[6] B. Gwalani, M. Olszta, S. Varma, L. Li, A. Soulami, E. Kautz, S. Pathak, A. Rohatgi, P.V. Sushko, S. Mathaudhu, Extreme shear-deformation-induced modification of defect structures and hierarchical microstructure in an Al-Si alloy, Communications Materials, 1 (2020) 1-7. 